Article

\title{
Performance of LiCl Impregnated Mesoporous Material Coating over Corrugated Heat Exchangers in a Solid Sorption Chiller
}

\author{
Hongzhi Liu ${ }^{1}$, Katsunori Nagano ${ }^{2, *}$ and Junya Togawa ${ }^{2}$ \\ 1 Department of Building Environment and Energy Engineering, University of Shanghai for Science and \\ Technology, 516 Jungong Road, Shanghai 200093, China; liuhongjuezhi@hotmail.com \\ 2 Environmental System Research Laboratory, Hokkaido University, N13-W8 Sapporo 060-8628, Japan; \\ togawa@eng.hokudai.ac.jp \\ * Correspondence: nagano@eng.hokudai.ac.jp; Tel.: +81-117-066-285
}

Received: 22 May 2018; Accepted: 11 June 2018; Published: 14 June 2018

\begin{abstract}
The composite material made by impregnating 40 wt. \% lithium chloride ( $\mathrm{LiCl})$ into the mesopores of a kind of natural porous rock (Wakkanai Siliceous Shale: WSS) micropowders (short for "WSS + 40 wt. \% LiCl") had been developed previously, and can be regenerated below $100{ }^{\circ} \mathrm{C}$ with a cooling coefficient of performance (COP) of approximately 0.3 when adopted as a sorbent in a sorption cooler. In this study, experiments have been carried out on an intermittent solid sorption chiller with the WSS + 40 wt. \% LiCl coating over two aluminum corrugated heat exchangers. Based on the experimental condition (regeneration temperature of $80{ }^{\circ} \mathrm{C}$, condensation temperature of $30{ }^{\circ} \mathrm{C}$ in the desorption process; sorption temperature of $30^{\circ} \mathrm{C}$ and evaporation temperature of $12{ }^{\circ} \mathrm{C}$ in the sorption process), the water sorption amount changes from $20 \mathrm{wt}$. \% to $70 \mathrm{wt}$. \% in one sorption cooling cycle. Moreover, a specific cooling power (SCP) of $86 \mathrm{~W} / \mathrm{kg}$, a volumetric specific cooling power (VSCP) of $42 \mathrm{~W} / \mathrm{dm}^{3}$, and a specific sorption power of $170 \mathrm{~W} / \mathrm{kg}$ can be achieved with a total sorption and desorption time of $20 \mathrm{~min}$. The obtained cooling COP is approximately 0.16.
\end{abstract}

Keywords: solid sorption chiller; lithium chloride ( $\mathrm{LiCl})$; composite sorbent; cooling COP

\section{Introduction}

The technology of a solid-gas sorption cooling and heating system has attracted intense interest because of its effectiveness to utilize renewable energy and store industrial waste heat. Moreover, this technology is ecological friendly as it does not use chlorofluorocarbons (CFCs) and hydrochlorofluorocarbons (HCFCs) as refrigerants, which are widely used in conventional vapor compression heating and cooling systems [1].

Comprehensive studies about sorption heating and cooling have been carried out from the points of novel sorbents (e.g., bi-salt and tri-salt composite sorbents-ammonia [2], microporous silica gel impregnated with calcium chloride-water [3], compound adsorbent of macroporous silica gel/LiCl-methanol [4], composite sorbent $\mathrm{CaClBr} /$ silica-methanol [5], selective water sorbents (SWSs) [6,7], silica Siogel-water [8], fiber silico-aluminophosphate (SAPO-34)-water [9], and $\mathrm{LiBr} /$ silica-ethanol [10]) and systems (e.g., packed bed with Mitsubishi AQSOA-FAM-Z02 advanced adsorbent [11], coated type bed with SWSs [12], granulated bed of composite sorbent [13], packed bed of $\mathrm{CaCl}_{2}$-in-silica gel-water system [14]). The common refrigerants adopted in sorption heating and cooling systems are ammonia, methanol, ethanol, and water [15]. Water was chosen as the refrigerant in this study because of its high latent heat of vaporization, thermal stability, non-flammability, non-toxicity, and typical environmental safety. When sorbent with a certain amount of water is heated during the regeneration process, the water vapor is generated and then condenses in 
the condenser to release heat. For the opposite process, cooling energy can be obtained in an evaporator because of water evaporation, and the evaporated water vapor binds to the sorbent during the sorption process [15]. Several novel porous solids with water as refrigerant are being researched in sorption heating and cooling systems: silica gel, FAM-01 and FAM-02 developed by Mitsubishi Plastics Ltd. (Tokyo, Japan), metal-organic frameworks (MOFs), and various composite sorbents [16]. Among these sorbents, composite sorbents are considered to be promising to enhance the efficiency of the sorption cooling and heating system by means of a target-oriented design of the sorbent specified for a particular cycle. Composites with two components can offer the opportunity for nano-tailoring the sorption properties by varying the confined salt chemical nature and content, porous structure of host matrix, and synthesis conditions $[16,17]$.

Two basic configurations for the composite sorbents-water working pairs were described in the literatures; namely, (1) packed bed sorbent contacting with the heat transfer surface, and (2) sorbent coating on the heat exchanger surface. For the packed bed sorbent cooling systems, Restuccia et al. $[6,18]$ developed an adsorptive cooling system with packed SWS-1L (mesoporous silica gel impregnated with $\mathrm{CaCl}_{2}$ ) inside a high-efficiency heat exchanger. A mean SCP of 20-40 W/ $\mathrm{kg}$ of adsorbent and a cooling COP of $0.4-0.6$ were obtained when the $T_{\text {re }}$ was $95^{\circ} \mathrm{C}, T_{\text {con }}$ was $35^{\circ} \mathrm{C}$, and $T_{\mathrm{ev}}$ was $10^{\circ} \mathrm{C}$. Freni et al. [19] tested the performance of a packed bed sorption chiller using SWS-8L (silica modified by $\left.\mathrm{Ca}\left(\mathrm{NO}_{3}\right)_{2}\right)$. At the operation condition of $T_{\mathrm{ev}}=15^{\circ} \mathrm{C}, T_{\text {con }}=30^{\circ} \mathrm{C}$, and $T_{\text {re }}=90-95^{\circ} \mathrm{C}$, the cooling COP increased from 0.28 to 0.41 , while the SCP decreased from $389 \mathrm{~W} / \mathrm{kg}$ to $190 \mathrm{~W} / \mathrm{kg}$ when the cycle time changed from $8 \mathrm{~min}$ to $30 \mathrm{~min}$. The performance of the packed bed sorption chiller using $\mathrm{LiNO}_{3}$ impregnated into silica gel (SWS-9L: silica modified by lithium nitrate) was tested by optimizing of the relative duration of the isobaric adsorption and desorption stages [20]. When the sorption chiller was driven by a lower temperature heat $\left(<90^{\circ} \mathrm{C}\right)\left(T_{\text {re }}\right.$ was $75^{\circ} \mathrm{C}, T_{\text {con }}$ was $30^{\circ} \mathrm{C}$, and $T_{\mathrm{ev}}$ was $10^{\circ} \mathrm{C}$ ), the cooling COP of 0.155 and SCP of $193 \mathrm{~W} / \mathrm{kg}$ still remained reasonable.

Though the above researched composites adopted in the sorption chillers showed relatively good performance, the main matrix is silica gel, which is a type of amorphous silica. It has been proven that the pores of silica gel increase in size when more than $5 \mathrm{wt}$. \% chloride is impregnated into the pores [21], making it inappropriate for long-term use. Therefore, a new composite with high stability was developed by impregnating $\mathrm{LiCl}$ into pores of mesoporous WSS [22]. $\mathrm{LiCl}$ is usually used as the liquid desiccant [23-25] or liquid absorption chiller [26,27]; its higher exergetic efficiency and long-term stability [28] is thought to be suitable as the other main component of the composite sorbent for a sorption chiller. For the prototype of the sorbent packed sorption cooler built in our previous research [29], the WSS $+40 \mathrm{wt}$. \% $\mathrm{LiCl}$ can contribute to getting a cooling COP of 0.3 and SCP of $70 \mathrm{~W} / \mathrm{kg}$, when it was regenerated at a temperature as low as $80^{\circ} \mathrm{C} ; T_{\text {con }}=30^{\circ} \mathrm{C}$, and $T_{\mathrm{ev}}=10^{\circ} \mathrm{C}$ with a cycle time of $30 \mathrm{~min}$. This indicated that the sorption cooling system using WSS $+40 \mathrm{wt} . \% \mathrm{LiCl}$ can be applied in low grade heat (solar thermal energy and industrial waste heat) utilization systems. However, heat and mass transfer improvement of the system is still needed to get a higher efficiency.

When compared with the introduced pelletized bed, the coated heat exchanger ensures better heat transfer properties [12], which can ensure good dynamics of the sorption/desorption cycle accompanying a shorter cycle duration. The coated sorbents can sorb water more efficiently [30] because of their faster sorption kinetics [31], and thus can deliver higher SCP. Freni et al. improved the adsorptive cooling system with packed SWS-1L (mesoporous silica gel impregnated with $\mathrm{CaCl}_{2}$ ) $[6,18]$ by developing a sorption chiller based on a heat exchanger coated with a compact layer of SWS-1L. Higher SCP of 150-200 W/ kg and a cooling COP ranging between 0.15 and 0.3 were obtained within a cycle time of $10-20 \mathrm{~min}$ when the SWS- $1 \mathrm{~L}$ was regenerated at $90-100^{\circ} \mathrm{C}, T_{\text {con }}=35^{\circ} \mathrm{C}, T_{\text {sor }}=15-20^{\circ} \mathrm{C}$, and $T_{\mathrm{ev}}=10^{\circ} \mathrm{C}$ [12]. The interesting result of the coated heat exchanger obtained from the above research and our previous research on the sorption cooler has stimulated us to take a necessary step for the development of the WSS $+40 \mathrm{wt}$. \% LiCl coated type heat exchanger installed sorption chiller.

Consequently, in this study, an innovative intermittent sorption chiller with WSS sorbent coating over corrugated heat exchangers is presented and tested. The developed sorption chiller consists of 
two aluminum corrugated heat exchangers coated with WSS $+40 \mathrm{wt}$. $\% \mathrm{LiCl}$ in the reactor and a spiral fin tube heat exchanger in the evaporator/condenser. The heat and mass transfer of the composite material is expected to be improved by the high-efficiency corrugated heat exchanger with extensive fin area, when compared with the packed sorbent in our previous research. The thermodynamic and experimental performances of the WSS $+40 \mathrm{wt}$. \% $\mathrm{LiCl}$ for the developed solid sorption chiller system will be evaluated.

\section{Experiments}

WSS is a natural mesoporous mudstone that is sourced in the north part of Hokkaido Island in Japan. It is naturally derived from diatoms and planktonic organisms composed mainly of silicon dioxide. As a result of the increase of temperature and pressure, diatomaceous mudstone changes to siliceous shale, and scale-like crystals of Opal-CT can be observed in WSS [32]. The main composition of WSS, shown in Table 1, was measured using a HORIBA X-ray Fluorescence Analyzer MESA-500. It can be seen that the main compounds are $\mathrm{SiO}_{2}, \mathrm{Al}_{2} \mathrm{O}_{3}$, and $\mathrm{Fe}_{2} \mathrm{O}_{3}$, and it is a kind of diatomaceous earth.

Table 1. Chemical composition of natural Wakkanai Siliceous Shale (WSS).

\begin{tabular}{cc}
\hline Compound & Concentration (wt. \%) \\
\hline $\mathrm{SiO}_{2}$ & 87.09 \\
$\mathrm{Al}_{2} \mathrm{O}_{3}$ & 8.09 \\
$\mathrm{Fe}_{2} \mathrm{O}_{3}$ & 3.39 \\
$\mathrm{~K}_{2} \mathrm{O}$ & 0.78 \\
$\mathrm{TiO}_{2}$ & 0.41 \\
$\mathrm{CaO}$ & 0.21 \\
$\mathrm{~V}_{2} \mathrm{O}_{5}$ & 0.03 \\
\hline
\end{tabular}

It has been confirmed that the composite material made by impregnating chloride into the mesopores of WSS is stable because of WSS's crystallized structure [29,32]. The composite material made by impregnating $\mathrm{LiCl}$ into the mesopores of WSS has shown high stability with lower regeneration temperature when compared with the composite material made by impregnating $\mathrm{CaCl}_{2}$ into WSS [22]. The physical properties, including pore size distribution and pore volume; sorption properties, such as water sorption isosters and sorption isotherms; and thermal properties of specific heat capacity and activation energy of the composite material WSS + $\mathrm{LiCl}$ were also tested in the research work reported in Jiang et al. [25]. Among the four developed composite samples, WSS $+40 \mathrm{wt}$. \% LiCl exhibited the best performance.

\subsection{The Sorbent Coated Heat Exchanger}

The corrugated heat exchanger, before and after being coated with the WSS $+40 \mathrm{wt}$. \% $\mathrm{LiCl}$, is shown in Figure 1. The main features of the composite material coated heat exchangers are listed in Table 2. The effective heat transfer area of the rectangular aluminum heat exchanger is $150 \times 150 \mathrm{~mm}$, and the overall dimensions are $170 \times 150 \times 25 \mathrm{~mm}$. The coating procedure is listed as follows:

1. The micropowders of WSS with peak particle diameter of $5 \mu \mathrm{m}$ were dried at $120^{\circ} \mathrm{C}$ for $24 \mathrm{~h}$.

2. The solution of $\mathrm{LiCl}$ was prepared first, and the corresponding amount of WSS was added to make the slurry of WSS and $\mathrm{LiCl}$. The slurry was vacuumed to make sure the $\mathrm{LiCl}$ solution got into the pores of WSS.

3. The corrugated aluminum heat exchanger was dip-coated with the slurry of WSS and LiCl without any binder, because the fine particles of WSS clay act as a kind of binder. There are no composite powder or $\mathrm{LiCl}$ drops after the coating procedure.

4. The coated heat exchanger was left open to the air for $24 \mathrm{~h}$ for air drying, before being heated at $120^{\circ} \mathrm{C}$ (the temperature was chosen according to the result obtained in Figure 9 in Liu et al. [22]) for $24 \mathrm{~h}$ to get its dry weight. 


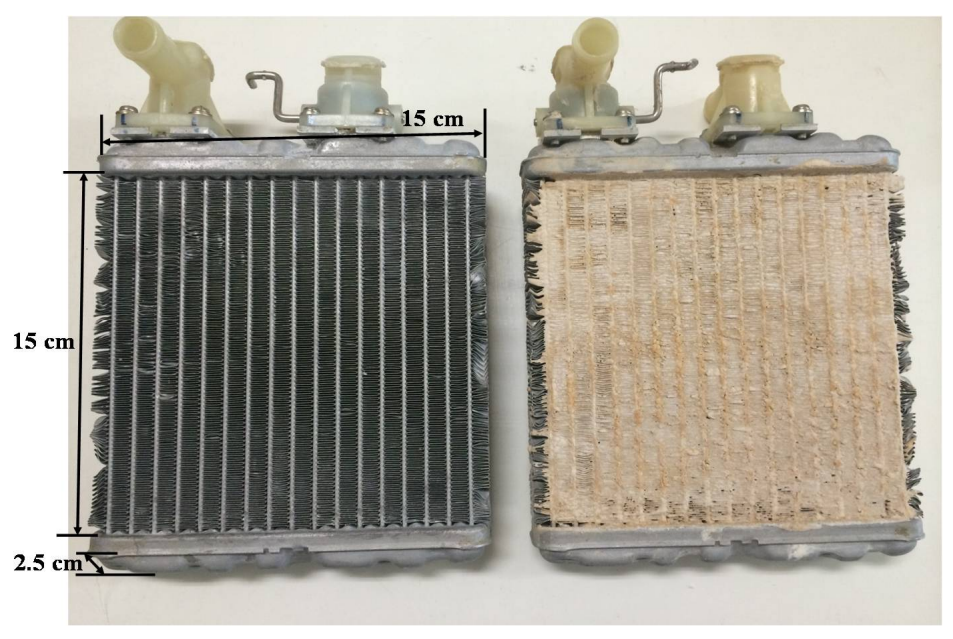

Figure 1. Corrugated heat exchanger before being coated (left), and after being coated (right) with Wakkanai Siliceous Shale (WSS) + 40 wt. \% lithium chloride ( $\mathrm{LiCl})$.

Table 2. Main features of the sorbent coated heat exchangers in the reactor.

\begin{tabular}{cc}
\hline Parameters & Value \\
\hline Total metal mass of one heat exchanger $(\mathrm{kg})$ & 0.454 \\
Total volume of one heat exchanger $\left(\mathrm{m}^{3}\right)$ & $0.5625 \times 10^{-3}$ \\
Heat transfer area of one heat exchanger $\left(\mathrm{m}^{2}\right)$ & $6.375 \times 10^{-2}$ \\
Coating density $\left(\mathrm{kg} / \mathrm{m}^{3}\right)$ & 0.143 \\
Total mass of the coated material on a heat exchanger $(\mathrm{kg})$ & 254.2 \\
Number of coated heat exchangers inside reactor $(-)$ & 2 \\
Total mass of the lithium chloride $(\mathrm{LiCl})(\mathrm{kg})$ & 0.1144 \\
\hline
\end{tabular}

\subsection{Experimental Setup}

The schematic diagram of the experimental setup is shown in Figure 2. It consists of a vacuum reactor with two sorbent coated heat exchangers inside and an evaporator/condenser with a spiral fin tube heat exchanger inside.

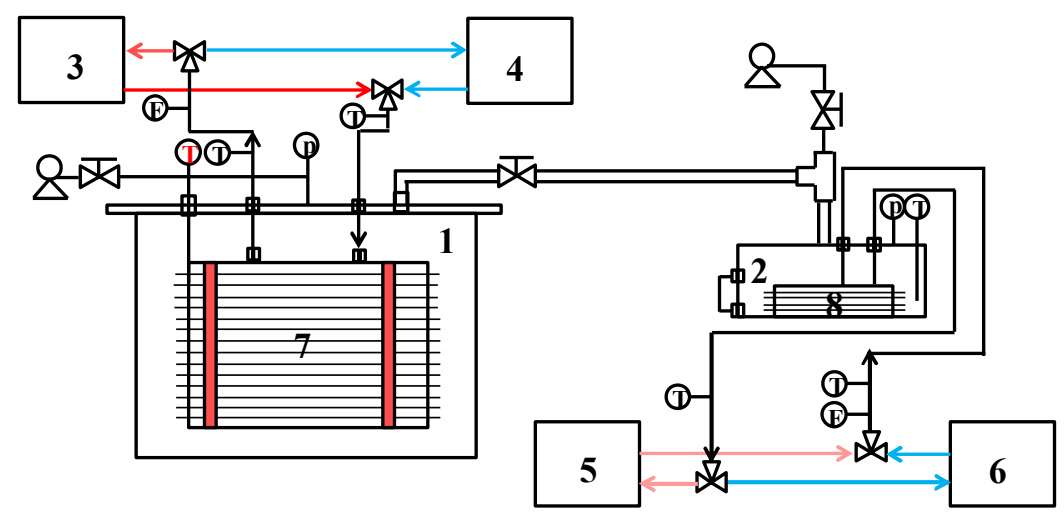

1. reactor

2. condenser/evaporator

3. circulating high temperature thermostatic bath

4. circulating medium temperature thermostatic bath

5. circulating medium temperature thermostatic bath

6. circulating low temperature thermostatic bath

7. corrugated type heat exchanger coated with material

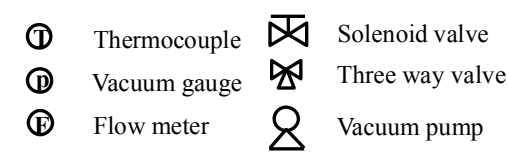

8. Spiral heat exchanger

Figure 2. Schematic diagram of experimental setup. 
During the sorption process, the water vapor evaporates in 2 (evaporator), and the produced cooling energy is taken away by low temperature thermostatic bath 6 . The evaporated water vapor flows through the connection valve, and is sorbed by the composite sorbent coating over the surface of heat exchangers inside of 1 (reactor) to release sorption heat, which is taken away by the medium temperature thermostatic bath 4 . On the other hand, heat from the high temperature thermostatic bath is supplied to the corrugated heat exchangers inside 1 (reactor), desorption of the sorbent occurs, and water vapor is generated. The desorbed water vapor condenses in 2 (condenser), and the condensation heat is taken away by medium temperature thermostatic bath 5 .

The picture of the experimental setup is shown in Figure 3, with reactor on the left side and condenser/evaporator on the right side. There is a ball valve connecting the reactor and the evaporator/condenser, and the inner diameter of the connecting tube is $12 \mathrm{~mm}$ and length is $30 \mathrm{~cm}$. The diameter of the evaporator/condenser is $10 \mathrm{~cm}$, and there is a spherical fin tube inside with a diameter of $6.35 \mathrm{~mm}$. Four thermostatic water baths simulate the heat source and sinks as described above. Water is used as external heat transfer fluid inside the thermostatic water baths.

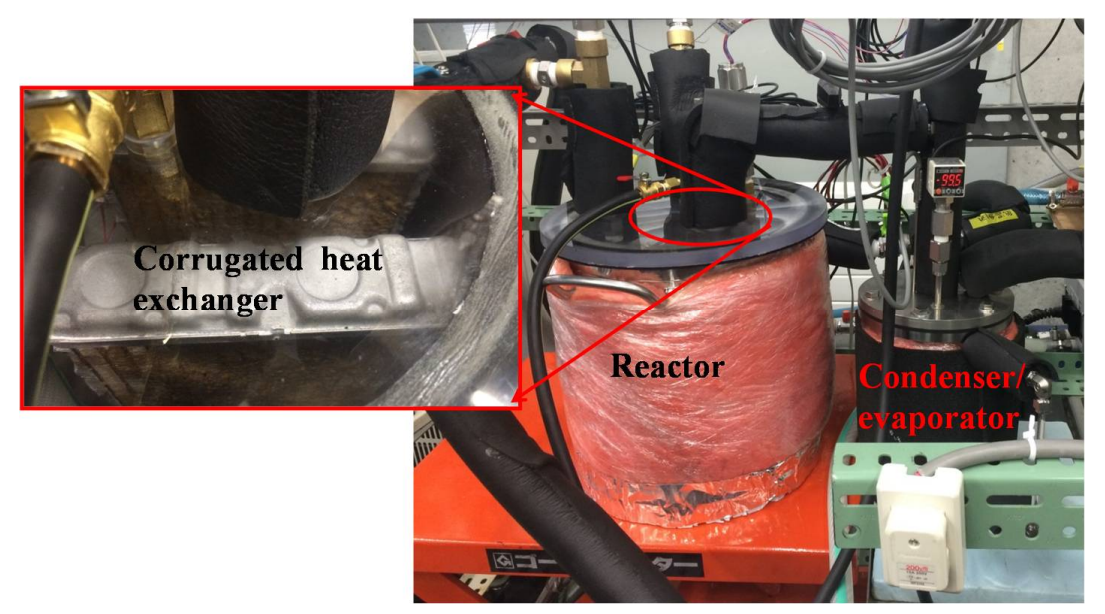

Figure 3. The testing experimental setup for producing cooling energy.

Temperature sensors of Pt100 thermal resistances were fitted in the inlet/outlet of each heat transfer circuit. The flow rates of the respective heat fluids were measured by two electromagnetic flow meters with an accuracy of $\pm 0.6 \%$. Four T-type thermocouples were inserted into the interval of two fins of the coated heat exchangers at different positions, whose mean temperature was considered as the temperature of the composite sorbent during the test. The water temperatures inside the condenser/evaporator were measured by Pt100 thermal resistances. The reacted water amounts could be measured by level gauge sets on the condenser/evaporator. Two digital vacuum gauges were connected to the reactor and the condenser/evaporator, respectively. The pressure was measured by a digital pressure indicator, with accuracy of $\pm 1.0 \%$ full scale. The testing facility was equipped with data acquisition equipment. The characteristics of the measuring system to evaluate the performance of the prototype are given in Table 3.

Table 3. Description of each measurement parameter.

\begin{tabular}{ccc}
\hline Component & Type & Properties \\
\hline Sorbent temperature & $\mathrm{T}$ & $-200<\mathrm{T}<350{ }^{\circ} \mathrm{C}, \pm 0.5^{\circ} \mathrm{C}$ \\
Water temperature & Pt100 & Screw-in sensor, $-40<\mathrm{T}<150{ }^{\circ} \mathrm{C}, \pm 0.15 \%$ \\
Pressure sensor & Digital pressure indicator & $-100 \mathrm{kPa}<p<100 \mathrm{kPa}, \pm 1.0 \%$ full scale \\
Flow meter & Electromagnetic flow sensor & $\mathrm{G}<5 \mathrm{~L} / \mathrm{min} .,-25^{\circ} \mathrm{C}<\mathrm{T}<80^{\circ} \mathrm{C}, \pm 0.6 \%$ full scale \\
Data logger & Digital measuring station & Sample rate every $125 \mathrm{~ms}, \pm 0.05 \%$ \\
\hline
\end{tabular}


The mass and volumetric specific cooling power SCP and VSCP were calculated according to the following equations [12]:

$$
\begin{gathered}
\mathrm{SCP}=\frac{\sum_{\tau_{3}}^{\tau_{4}} \rho_{\mathrm{H}_{2} \mathrm{O}} G_{\mathrm{H}_{2} \mathrm{O}, \mathrm{ev}} C_{\mathrm{P}_{,} \mathrm{H}_{2} \mathrm{O}}\left(T_{\text {in,ev }}-T_{\text {out,ev }}\right) \Delta \tau_{\mathrm{ev}}}{m_{\text {dry }} \tau_{\text {cycle }}} \\
\mathrm{VSCP}=\frac{\sum_{\tau_{3}}^{\tau_{4}} \rho_{\mathrm{H}_{2} \mathrm{O}} G_{\mathrm{H}_{2} \mathrm{O}, \mathrm{ev}} C_{\mathrm{P}, \mathrm{H}_{2} \mathrm{O}}\left(T_{\mathrm{in}, \mathrm{ev}}-T_{\mathrm{out}, \mathrm{ev}}\right) \Delta \tau_{\mathrm{ev}}}{\mathrm{V}_{\text {hex }} \tau_{\text {cycle }}}
\end{gathered}
$$

where the $T_{\text {in,ev }}-T_{\text {out,ev }}$ refers to the temperature difference between the inlet and outlet of the external heat transfer water of the evaporator during the sorption process. $\tau_{3}$ to $\tau_{4}$ represents the isobaric sorption time (evaporation time).

The evaporated water vapor will flow to the reactor and be sorbed by the composite material inside, and the sorption heat can be released and taken away by the fluid inside the heat exchanger. In this case, the specific heating power $q_{\mathrm{SH}}$ can be obtained by the following equation:

$$
q_{\mathrm{S}, \mathrm{H}}=\frac{\sum_{\tau_{3}}^{\tau_{4}} \rho_{\mathrm{H}_{2} \mathrm{O}} G_{\mathrm{H}_{2} \mathrm{O}, \mathrm{sor}} C_{P, \mathrm{H}_{2} \mathrm{O}}\left(T_{\text {in,sor }}-T_{\text {out }, \mathrm{sor}}\right) \Delta \tau_{\mathrm{ev}}}{m_{\text {dry }} \tau_{\text {cycle }}}
$$

where $T_{\mathrm{in}, \text { sor }}-T_{\text {out,sor }}$ refers to the temperature difference between the inlet and outlet of the external heat transfer water of the reactor during the sorption process.

While in the regeneration process, the composite material with a certain water uptake will be decomposed into the relative dry material and the water vapor. The desorbed water vapor goes through the connecting tube and condenses in the condenser. The condensation heat in this case can be taken away by the water inside the heat exchanger in the condenser. The specific condensation power $q_{\mathrm{S}, \mathrm{con}}$ was defined as follows:

$$
q_{\mathrm{S}, \mathrm{con}}=\frac{\sum_{\tau_{1}}^{\tau_{2}} \rho_{\mathrm{H}_{2} \mathrm{O}} G_{\mathrm{H}_{2} \mathrm{O}, \text { con }} C_{P, \mathrm{H}_{2} \mathrm{O}}\left(T_{\text {in,con }}-T_{\text {out }, \text { con }}\right) \Delta \tau_{\text {con }}}{m_{\text {dry }} \tau_{\text {cycle }}}
$$

The cooling COP can be calculated as follows:

$$
\mathrm{COP}=\frac{\sum_{\tau_{3}}^{\tau_{4}} \rho_{\mathrm{H}_{2} \mathrm{O}, \mathrm{ev}} G_{\mathrm{H}_{2} \mathrm{O}, \mathrm{ev}} C_{P, \mathrm{H}_{2} \mathrm{O}}\left(T_{\text {in,ev }}-T_{\text {out,ev }}\right) \Delta \tau_{\mathrm{ev}}}{\sum_{\tau_{0}}^{\tau_{2}} \rho_{\mathrm{H}_{2} \mathrm{O}, \mathrm{re}} G_{\mathrm{H}_{2} \mathrm{O}, \mathrm{re}} C_{P, \mathrm{H}_{2} \mathrm{O}}\left(T_{\text {in,re }}-T_{\text {out,re }}\right) \Delta \tau_{\mathrm{re}}}
$$

where $T_{\text {in,re }}-T_{\text {out,re }}$ refers to the water temperature difference between the inlet and outlet of the external heat transfer of the reactor during the regeneration process. $\tau_{0}$ to $\tau_{2}$ represents the isosteric heating time and desorption time, and $\tau_{1}$ to $\tau_{2}$ represents the desorption time after the isosteric heating. It is considered that the obtained SCP, VSCP, specific heating power $q_{\mathrm{SH}}$, specific condensation power $q_{\mathrm{S} \text {,con, }}$ and cooling COP are influenced by thermodynamic and kinetic properties of the sorbent, heat transfer properties of the heat exchanger in the reactor and condenser/evaporator, and the mass transfer of the water vapor through the composite material, as well as the sensible heat due to the weight of the heat exchanger, the heat loss, and the residual air inside the device [12].

\subsection{Experimental Procedure}

The Clapeyron diagram of WSS $+40 \mathrm{wt}$ \% LiCl was obtained in our previous study [29], which relates the equilibrium pressure and temperature at the fixed water sorption amount. For a space cooling system, the inlet of the chiller water is set as $12{ }^{\circ} \mathrm{C}$. The desorption temperature of $80^{\circ} \mathrm{C}$ is optimal to obtain a high cooling $\mathrm{COP}$ and high $\mathrm{SCP}$ by evaluating the effect of regeneration temperature on the cooling performance of the sorption cooler using WSS $+40 \%$ wt. $\% \mathrm{LiCl}$. A cooling experimental cycle $\left(T_{\text {in,ev }}=12{ }^{\circ} \mathrm{C}, T_{\text {in,sor }}=30{ }^{\circ} \mathrm{C}, T_{\text {in,con }}=30{ }^{\circ} \mathrm{C}, T_{\text {in,re }}=80{ }^{\circ} \mathrm{C}\right)$ had been decided in this study according to the optimal experimental condition for WSS $+40 \% \mathrm{wt}$. \% $\mathrm{LiCl}$ obtained in our previous 
study [29]. Before starting the experiment, the whole device was vacuumed by a connected vacuum pump for at least $24 \mathrm{~h}$. The cooling cycle was conducted by the following procedures:

1. The sorbent coated heat exchanger was cooled by the medium temperature thermostatic bath $\left(T_{\mathrm{in}, \text { sor }}=30^{\circ} \mathrm{C}\right)$, and the water inside the evaporator was controlled by a low temperature thermostatic bath at the same time $\left(T_{\mathrm{in}, \mathrm{ev}}=12{ }^{\circ} \mathrm{C}\right)$.

2. When the pressure of the reactor decreased to the target pressure of the evaporator, the connecting valve between the evaporator and reactor was opened to start the heat release process. The connecting valve would be closed until the sorption time reached $10 \mathrm{~min}$.

3. The composite material was heated by the fluid from the high temperature circulating the thermostatic water bath. The water inside the condenser was controlled by the medium temperature thermostatic water bath at the same time $\left(T_{\text {in,re }}=80^{\circ} \mathrm{C}, T_{\text {in, con }}=30^{\circ} \mathrm{C}\right)$.

4. The valve connecting the reactor and condenser was opended to start the regeneration release process until the pressures of the two containers were the same. The condenser and reactor remained connected and the composite material was still heated until the desorption process was completed. The continued cycle began from step (1).

\section{Results and Discussion}

\subsection{The Sorption Cycle on Clapeyron Diagram}

The tests were carried out according to the experimental condition described in Section $2.3\left(T_{\text {in,ev }}=12{ }^{\circ} \mathrm{C}\right.$, $T_{\text {in,con }}=30^{\circ} \mathrm{C}$, and $T_{\text {in,re }}=80^{\circ} \mathrm{C}$ ). The real cooling cycle on the Clapeyron diagram obtained in this research is presented in Figure 4, which relates the equilibrium pressure and temperature at fixed water uptake. The isosteric chart of the WSS $+40 \mathrm{wt}$. \% LiCl was measured at the equilibrium conditions using the thermogravimetric method [29]. The cooling cycle consists of the isosteric cooling process $2 \rightarrow 3$, the sorption process $3 \rightarrow 4$, the isosteric heating process $4 \rightarrow 1$, and the desorption process $1 \rightarrow 2$. It can be seen that the isosteric heating and cooling phases follow the theoretical cycle in general. Whereas the isobaric desorption phase deviates from the theoretical cycle, which is considered to be caused by the following two reasons: (1) the retard of the connection valve opening causes a pressure increasing in the desorption process before the water flows into and condenses in the condenser; (2) the mix of high temperature and medium temperature fluids supplied by two different thermostatic baths results in a lower supplied hot water temperature than the set value (cf. Figure 2). Then, it has to be heated gradually to the setting value by the thermostatic bath, thus resulting in a pressure increase. However, the above two problems are related with the thermal management of the components and the current sophisticated design of evaporator/condenser, which should be modified in our future work.

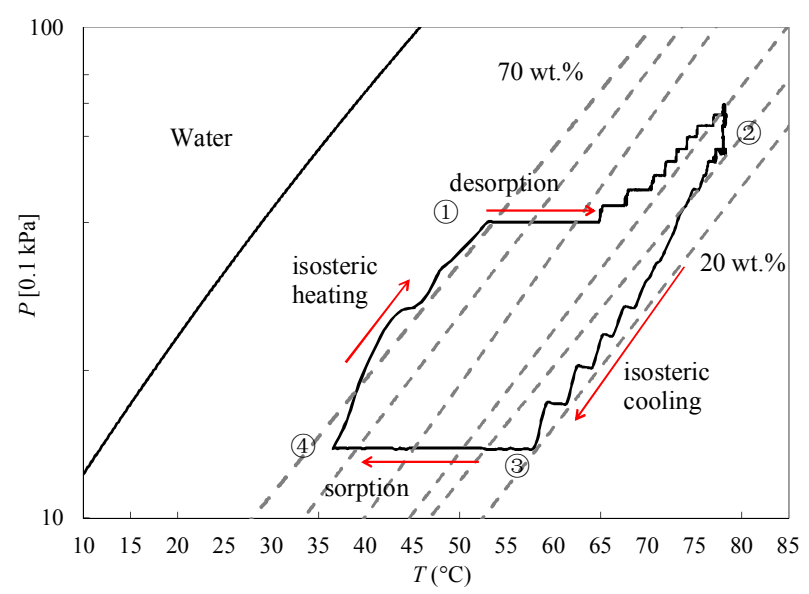

Figure 4. Typical experimental test on the WSS +40 wt. \% LiCl coated corrugated heat exchanger in the Clapeyron diagram. 
The important result obtained from the Clapeyron diagram is that the water uptake changes from $20 \mathrm{wt}$. \% to $70 \mathrm{wt}$. \%. It is well known that the water sorption can be characterized by water content $\omega=m_{\mathrm{H}_{2} \mathrm{O}}(P, T) / m_{\text {dry }}$ [33]. According to the phase diagram of $\mathrm{LiCl}-\mathrm{H}_{2} \mathrm{O}$ [34], in which the phase depends on the temperature and solution composition, $\mathrm{LiCl}$ may exist in many crystalline forms (anhydrous $\mathrm{LiCl}$, $\mathrm{LiCl} \cdot \mathrm{H}_{2} \mathrm{O}, \mathrm{LiCl} \cdot 2 \mathrm{H}_{2} \mathrm{O}, \mathrm{LiCl} \cdot 3 \mathrm{H}_{2} \mathrm{O}$, and $\mathrm{LiCl} \cdot 5 \mathrm{H}_{2} \mathrm{O}$ ). The sorption amounts $20 \mathrm{wt}$ \% and $70 \mathrm{wt}$ \% correspond to 66.7 and 36.3 mass \% $\mathrm{LiCl}$, respectively, in the phase diagram (cf. Figure 5). Because the composite material was previously prepared under the temperature of $120{ }^{\circ} \mathrm{C}$, for the first cooling cycle using this material, the $\mathrm{LiCl}$ in the pores of WSS changes from anhydrous $\mathrm{LiCl}+$ solution to $\mathrm{LiCl} \cdot \mathrm{H}_{2} \mathrm{O}+$ solution, and at last to $\mathrm{LiCl}$ solution after being sorbed $70 \mathrm{wt}$. \% water at $30^{\circ} \mathrm{C}$. Therefore, both the adsorption and absorption processes occur in the first cycle. While for the next several sorption/desorption cycles, $\mathrm{LiCl} \cdot \mathrm{H}_{2} \mathrm{O}$ + solution changes to $\mathrm{LiCl}$ solution after being sorbed $70 \mathrm{wt}$. \% water, as shown in Figure 5. However, Aristov et al. pointed out that the confinement of salt to mesopores can strongly influence the formation of crystal hydrates because of vapor-salt interactions. Their results indicated that the melting temperature of $\mathrm{CaCl}_{2}$ tetrahydrates and hexahydrates in the mesopores was depressed [35]. For the mesoporous host material, the typical melting temperature depression was about $15-30{ }^{\circ} \mathrm{C}$ [36]. Therefore, the phase diagram of $\mathrm{LiCl}$ used in this research is a general indication of $\mathrm{LiCl}$ phase change, and it is thought that the $\mathrm{LiCl}$ confined to the mesopores of WSS changes from anhydrous $\mathrm{LiCl}+$ solution to $\mathrm{LiCl} \cdot \mathrm{H}_{2} \mathrm{O}+$ solution, and at last to $\mathrm{LiCl}$ solution in the sorption process, considering the melting temperature depression.

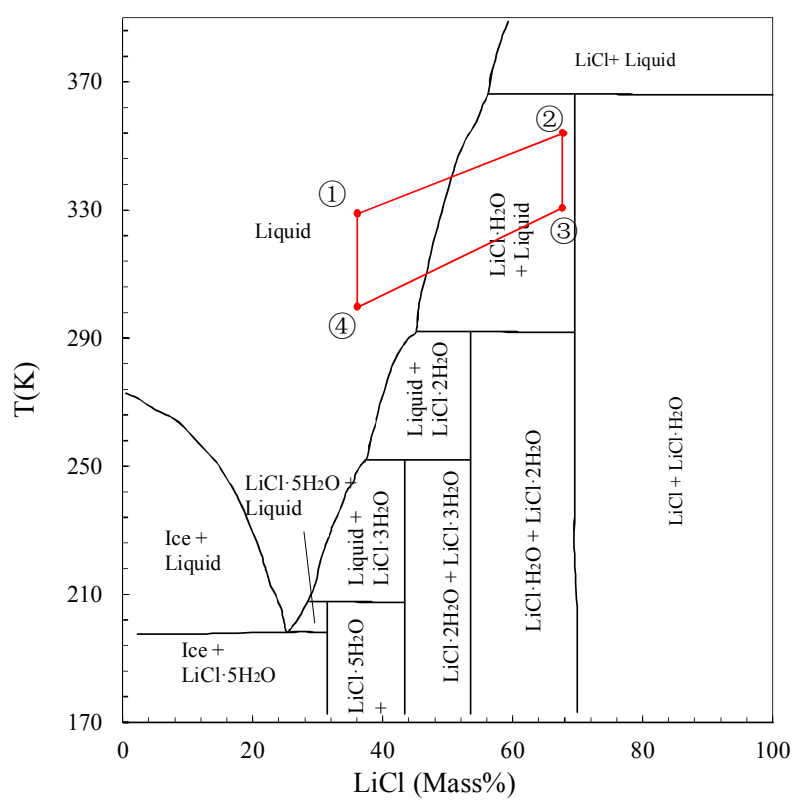

Figure 5. Phase diagram for the $\mathrm{LiCl}+\mathrm{H}_{2} \mathrm{O}$ system [37].

The water uptake changes from $20 \mathrm{wt}$. \% to $70 \mathrm{wt}$. \%, which means that for per unit weight dry WSS +40 wt. \% LiCl, $0.5 \mathrm{~g}$ water can ideally be sorbed and desorbed in a cycle. However, according to the recorded water level change in the evaporator, in the sorption process, almost a half of the ideal sorption amount changes were supplied by the evaporated water in the evaporator during a sorption time of $10 \mathrm{~min}$. Moreover, all of the sorbed water in the evaporation process was regenerated within a desorption time of $10 \mathrm{~min}$. This indicates that the relative high heat and mass transfer characteristics of the sorbent coated type heat exchanger inside the reactor are guaranteed a short isosteric sorption/desorption time of $10 \mathrm{~min}$.

\subsection{Performance of the Sorbent Coated Type Sorption Chiller}

Figure 6 shows the behavior of the average temperature of the composite sorbent and the inlet and outlet temperature of the heat exchanger on the reactor during one cycle. The total elapsed time 
is about $40 \mathrm{~min}$, while it is only $20 \mathrm{~min}$ in total for the sorption and desorption processes. The high temperature thermostatic bath and the medium temperature bath are connected to reactors through a long common tube, which results in the two totally different temperature fluids mixing, and then the fluid temperature for the regeneration is decreased below $70^{\circ} \mathrm{C}$. Therefore, the high temperature thermostatic bath needs to heat the heat transfer fluid up to $80^{\circ} \mathrm{C}$ for the desorption process to start. The time for hot water to be heated to the desired temperature of $80^{\circ} \mathrm{C}$ is almost $10 \mathrm{~min}$, so is the thermostatic bath in the evaporator/condenser side, which indicates that the improvement of the thermal management for the sorption chiller is necessary for the next step. However, it can be seen from Figure 6 that the good heat transfer between the composite sorbent and the heat exchanger can be proven by the small temperature difference between the composite temperature and the external heat transfer fluid.

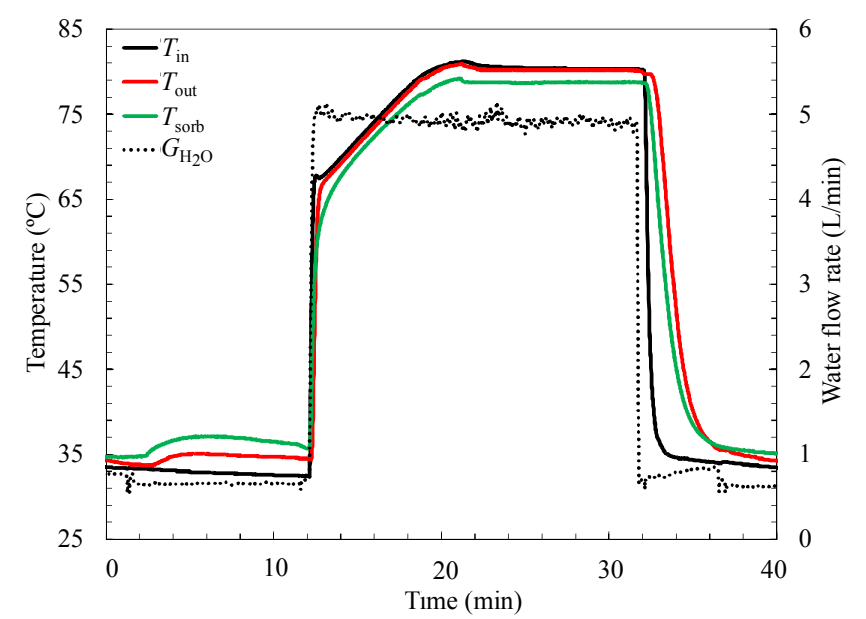

Figure 6. Temperature of the composite material; the inlet and outlet temperatures of the heat exchanger on the reactor side changes with time.

The water temperature inside the condenser/evaporator, and inlet and outlet temperatures of the heat exchanger on the condenser/evaporator in a cycle, are shown in Figure 7. The obvious temperature increase of the water in the regeneration process due to water vapor condensation can be observed. At the same time, the water temperature decrease from 2 to 12 min during the sorption process can also be detected.

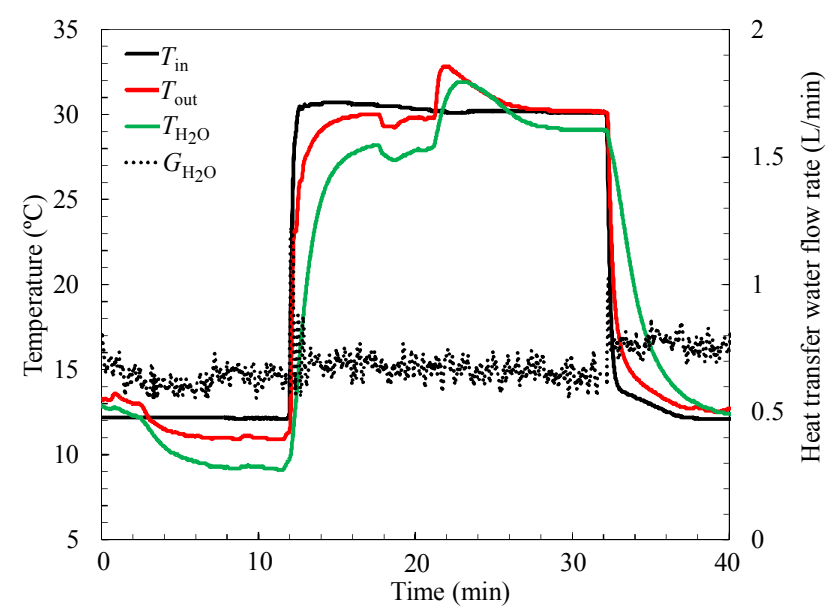

Figure 7. Temperature of the water inside condenser/evaporator; the inlet and outlet temperatures of the heat exchanger on the condenser/evaporator side changes with time. 
There were only two WSS $+40 \mathrm{wt}$. \% $\mathrm{LiCl}$ coated heat exchangers set inside the reactor and the total coated material's dry weight was $286 \mathrm{~g}$. Therefore, according to the results shown in Figure 7 , the total amount of water needed to be evaporated during the experiment in the evaporator was less than $100 \mathrm{~g}$. However, the diameter of the evaporator/condenser was $100 \mathrm{~mm}$, which means the spiral heat exchange area was insufficient when the evaporation water amount was small. Therefore, the outlet temperature of the heat exchanger in the evaporator is only $1^{\circ} \mathrm{C}$ lower than the inlet temperature, while the water's temperature is $3^{\circ} \mathrm{C}$ lower than the inlet water temperature, as shown in Figure 7. In the case of the sorption cooler developed in our previous research [1], the water temperature inside the evaporator was even $5{ }^{\circ} \mathrm{C}$ lower than the inlet temperature at the same experimental condition, due to the appropriate injected amount of water in the evaporator. However, in this study, in order to increase the heat exchange area, the injected water amount in the evaporator was $300 \mathrm{~g}$, which was more than three times that of the necessary amount $(<100 \mathrm{~g})$ during 10 min sorption time. The excessive amount of water inside the evaporator resulted in a relatively low water temperature decrease. This indicates that more effort should be made to improve the heat transfer properties of the evaporator/condenser, and thus further to enhance the performance of the system. Therefore, an optimal design of the heat exchanger for evaporator/condenser $[38,39]$ is necessary to obtain a high efficiency sorption chiller in future.

The temporary reactor pressure and evaporator/condenser pressure are shown in Figure 8. The pressure changes inside the two containers are consistent with the corresponding temperature change. It can be seen that the pressure difference is the driving force of the water vapor flowing between the reactor and evaporator/condenser. During the sorption process, the pressure of the evaporator is higher than that of the reactor, which is why the evaporated water vapor automatically flows to the reactor side. Whereas in the desorption process, the pressure of the reactor is larger than that of the condenser, which causes the desorbed water vapor to condense in the condenser.

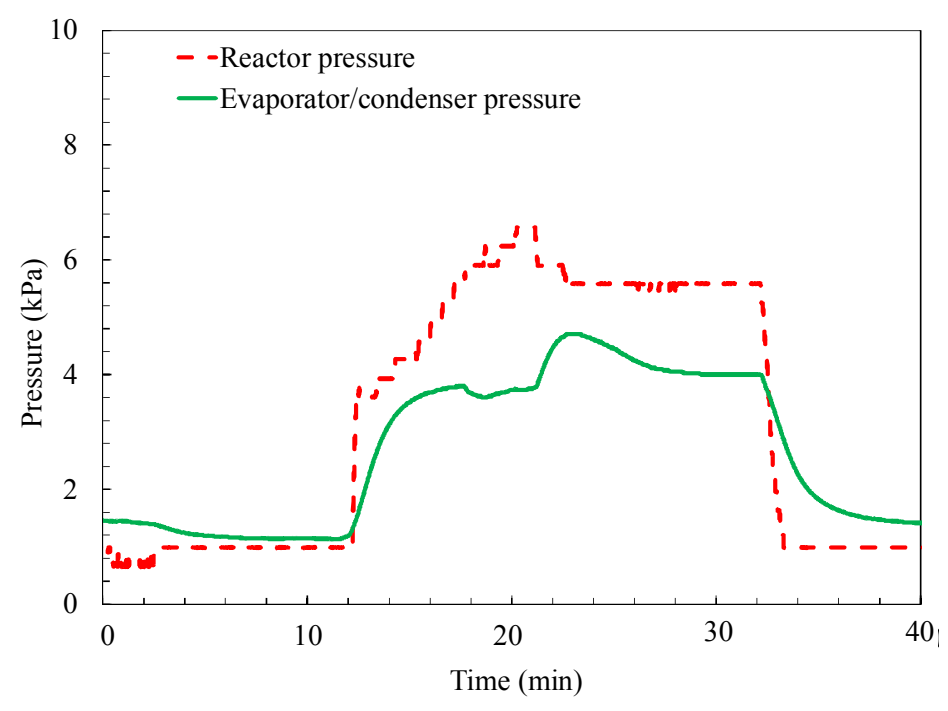

Figure 8. The temporary pressures inside the reactor and evaporator/condenser.

The instantaneous specific cooling power, specific heating power, specific condensation power (effective energy), and the input and extracted power from the reactor are illustrated in Figure 9. The instantaneous power is delivered by the heat exchangers of the reactor and the evaporator/condenser, respectively. This was calculated from the corresponding input and output temperature difference and the flow rate of the heat transfer fluid. Because there is only one reactor installed in the sorption chiller, the useful effect has to be produced intermittently. During the sorption process, the instantaneous cooling effect is about $200 \mathrm{~W} / \mathrm{kg}$ of dry WSS $+40 \mathrm{wt}$. $\% \mathrm{LiCl}$, while the instantaneous sorption heat released is about $400 \mathrm{~W} / \mathrm{kg}$ of dry WSS $+40 \mathrm{wt}$. $\% \mathrm{LiCl}$. 
The mass and volumetric specific cooling powers SCP and VSCP, calculated according to Equations (1) and (2), are $86 \mathrm{~W} / \mathrm{kg}$ and $42 \mathrm{~W} / \mathrm{dm}^{3}$, respectively, without considering the time caused by the mix of different temperature fluids. Whereas a higher specific sorption power is displayed as more than $170 \mathrm{~W} / \mathrm{kg}$. The specific condensation power is almost the same with that of the SCP, with a value of $72 \mathrm{~W} / \mathrm{kg}$. Under the same working condition with the packed bed sorption cooler, the calculated cooling COP according to Equation (5) is 0.16, without considering the time caused by the mix of fluids. The typical experimental errors of the cooling COP and SCP were calculated according to the method of combined uncertainty [40]. The result of this uncertainty study showed that the measuring errors of SCP and cooling COP were less than $10 \%$.

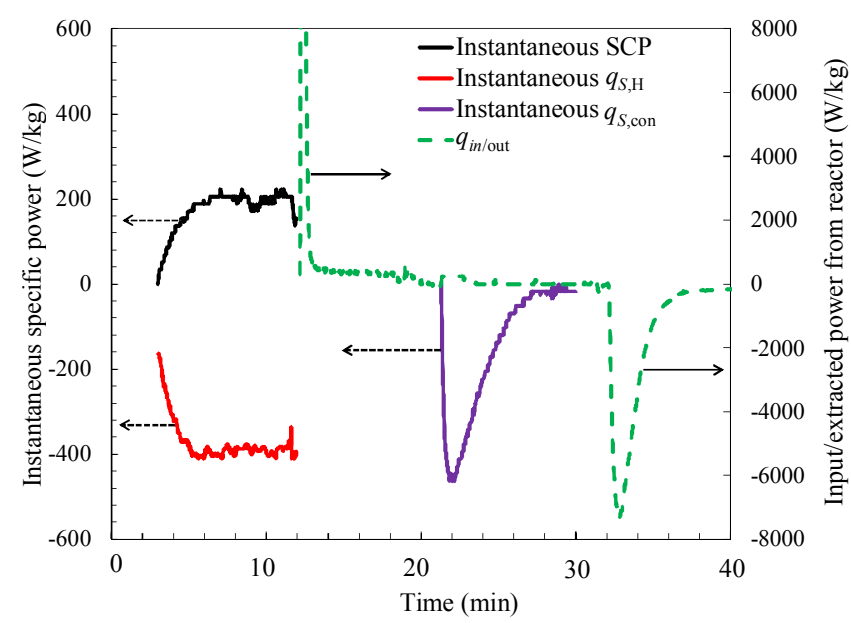

Figure 9. Instantaneous specific cooling and heating power as a function of time. SCP-specific cooling power.

\subsection{Performance Comparison}

The performance comparisons among the current sorption chiller, the previous developed sorption cooler adopting the same composite sorbent WSS $+40 \mathrm{wt}$. \% $\mathrm{LiCl}$ [29], and the SWS-1L coated heat exchanger type sorption chiller developed by Freni [12] are presented in Table 4.

Table 4. Cooling performance comparison. SWS—selective water sorbents; SCP—specific cooling power; $\mathrm{COP}$ - coefficient of performance.

\begin{tabular}{cccc}
\hline & $\begin{array}{c}\text { WSS + 40 wt. \% LiCl } \\
\text { Coated Heat Exchanger }\end{array}$ & $\begin{array}{c}\text { WSS + 40 wt. \% LiCl } \\
\text { Packed Bed [29] }\end{array}$ & $\begin{array}{c}\text { SWS-1L Coated } \\
\text { Heat Exchanger [12] }\end{array}$ \\
\hline Salt content $x(\%)$ & $40 \mathrm{wt} \%$ LiCl & $40 \mathrm{wt}$ \% $\mathrm{LiCl}$ & $33.7 \mathrm{wt} \% \mathrm{CaCl}_{2}$ \\
$\mathrm{SCP}(\mathrm{W} / \mathrm{kg})$ & 86 & $50-60$ & $150-200$ \\
Cycle time $t_{\text {cycle }}(\min )$. & 20 & 120 & $10-20$ \\
Cooling COP & 0.16 & $0.2-0.3$ & $0.15-0.3$ \\
Sorption/evaporation temperature $T_{\text {con }}\left({ }^{\circ} \mathrm{C}\right)$ & $30 / 12$ & $30 / 12$ & $(15-20) /(7-12)$ \\
Regeneration/condensation temperature $T_{\text {re }}\left({ }^{\circ} \mathrm{C}\right)$ & $80 / 30$ & $(80-90) / 30$ & $(95-100) / 35$ \\
\hline
\end{tabular}

Both cooling COP and SCP of the current study are lower than those of the novel coated type sorption chiller described in Freni et al. [12]. However, it is difficult to compare the performance of the WSS + $40 \mathrm{wt} . \% \mathrm{LiCl}$ coated sorption chiller with the SWS-1L coated sorption chiller simply from SCP and COP, because it is a small-scale experimental setup to prove whether or not the WSS $+40 \mathrm{wt}$ \% LiCl coated corrugated heat exchanger can be applied to a realistic sorption chiller. One of the causes of the not so high cooling COP is thought to be the large heat capacity of the thick stainless steel vessel without inner thermal insulation. In this case, the composite sorbent is not enough to match the weight of the vessel. Therefore, extra heat must be transferred to the vessel during 
regeneration process. On the other hand, the produced cooling energy in the evaporator would cool down the vessel of the evaporator during the sorption process.

The sorbent coated corrugated heat exchanger discussed in this study can reduce the sorption/desorption cycle when compared with the packed bed, although the cooling COP of the sorption chiller with the sorbent coated heat exchanger is lower than that of the packed bed. This is because the short sorption/desorption duration limits the effective amount of water vapor exchanged during one cycle [12].

Although the current thermal management system is not perfect, the SCP is still slightly higher than the SCP of the sorption cooler developed in our previous study [29]. This indicates that the WSS +40 wt. \% $\mathrm{LiCl}$ coated sorption chiller still shows its effectiveness to improve the SCP.

\subsection{Further Improvements and Considerations}

Based on the analysis of the experimental results, the WSS $+40 \mathrm{wt}$. $\% \mathrm{LiCl}$ has great potential to be a sorbent for the sorption chiller, and the sorbent coated corrugated heat exchanger has advantages to improve both the heat and mass transfer of the sorbent. Future improvements to achieve higher efficiency with higher SCP and cooling COP are as follows:

- Lower the heat capacity of vessels of the reactor and condenser/evaporator, and increase the mass ratio of sorbent/metal.

- Optimally design the corrugated heat exchanger in the reactor and heat exchanger in condenser/evaporator.

- Optimize the coating thickness of the sorbent and the coating manufacture; fully packed bed type, thin coating on fins, moderate thickness of coating layer, and so on.

- Install sorbent coated corrugated heat exchangers tightly into the evacuated reactor, while keeping proper gaps between each of the two heat exchangers, and in this case, a precise manifold should be made.

- Set a coat of thermal insulation material over both the inside and outside surface of the reactor and condenser/evaporator vessels.

- $\quad$ Add heat recovery process during the early several minutes after switching from the desorption to sorption process and from the sorption to desorption process.

- $\quad$ Add vapor recovery process for the last several seconds before switching different processes.

Of course, the long-term durability and the life span of the sorbent should be checked.

\section{Conclusions}

The experimental testing on the composite material WSS $+40 \mathrm{wt}$. \% $\mathrm{LiCl}$ coated heat exchanger sorption chiller was presented.

(1) The WSS $+40 \mathrm{wt}$. \% LiCl was coated on two corrugated heat exchangers, and it can work well as the sorbent in the developed lab-scale sorption chiller under regeneration temperature of $80^{\circ} \mathrm{C}$ and evaporation temperature of $12^{\circ} \mathrm{C}$.

(2) In one sorption cooling cycle, the water uptake changes from $20 \mathrm{wt}$. $\%$ to $70 \mathrm{wt}$. $\%$, which means that for per g dry WSS $+40 \mathrm{wt}$ \% $\mathrm{LiCl}, 0.5 \mathrm{~g}$ water can ideally be sorbed and desorbed in one cycle.

(3) The cycle time of the sorbent coated sorption chiller could be decreased compared with our previous packed bed sorption cooler under the same operating condition.

(4) The experimental results showed a SCP of $86 \mathrm{~W} / \mathrm{kg}$, VSCP of $42 \mathrm{~W} / \mathrm{dm}^{3}$, and specific sorption power of $170 \mathrm{~W} / \mathrm{kg}$ with a total sorption and desorption time of $20 \mathrm{~min}$. Based on the current operation condition (regeneration temperature of $80^{\circ} \mathrm{C}$, condensation temperature of $30^{\circ} \mathrm{C}$ in the desorption process; sorption temperature of $30^{\circ} \mathrm{C}$ and evaporation temperature of $12{ }^{\circ} \mathrm{C}$ in the sorption process), the obtained cooling COP is approximately 0.16 .

The low cooling COP is considered to be caused by the large heat capacity of the reactor vessel, which, compared with the amount of the adopted sorbent material, is overlarge. 
Scaling up, carefully high thermal insulating, and continuous operation using double reactors can enhance its efficiency with higher SCP.

Finally, the direction for the improvements of the sorption chiller is described. The sorption chiller adopted with WSS $+40 \mathrm{wt}$. \% $\mathrm{LiCl}$ will be improved based on the above considerations, within which thinner and larger-sized corrugated heat exchangers would be tightly inserted into the reactor.

Author Contributions: H.L., K.N. and J.T. drafted the work, and conceived and designed the experiments; H.L. performed the experiments and analyzed the data. H.L., K.N. and J.T. gave the final approval of the version to be published.

Funding: Japan Society for the Promotion of Science: 15K14297.

Acknowledgments: The authors would like to thank SUNPOT Co. Ltd. (Saitama, Japan) for their help with the manufacture of the vessels for the reactor and evaporator/condenser. Financial support from Japan Society for the Promotion of Science is greatly appreciated.

Conflicts of Interest: The authors declare no conflicts of interest.

\section{Abbreviations}

\begin{tabular}{|c|c|}
\hline WSS & Wakkanai Siliceous Shale \\
\hline WSS + 40 wt. $\% \mathrm{LiCl}$ & WSS impregnated with 40 wt. $\% \mathrm{LiCl}$ \\
\hline \multicolumn{2}{|l|}{ Nomenclature } \\
\hline $\mathrm{COP}$ & Coefficient of performance (-) \\
\hline$C_{P}$ & Specific heat capacity $(\mathrm{kJ} /(\mathrm{kg} \cdot \mathrm{K}))$ \\
\hline G & Flow rate of the fluid $\left(\mathrm{m}^{3} / \mathrm{s}\right)$ \\
\hline$m$ & Weight of sorbent $(\mathrm{g})$ \\
\hline$P$ & Pressure $(\mathrm{Pa})$ \\
\hline$q_{S}$ & Specific power (W/kg-sample) \\
\hline SCP & Specific cooling power $(\mathrm{W} / \mathrm{kg})$ \\
\hline$T$ & Temperature $\left({ }^{\circ} \mathrm{C}\right)$ \\
\hline$V$ & Volume $\left(\mathrm{m}^{3}\right)$ \\
\hline VSCP & Volumetric specific cooling power $\left(\mathrm{W} / \mathrm{dm}^{3}\right)$ \\
\hline \multicolumn{2}{|l|}{ Greek symbols } \\
\hline$\Delta \tau$ & Time interval (s) \\
\hline$\rho$ & Density $\left(\mathrm{kg} / \mathrm{m}^{3}\right)$ \\
\hline$\tau$ & Time (s) \\
\hline$\omega$ & Water sorption amount (g/g) \\
\hline \multicolumn{2}{|l|}{ Subscripts } \\
\hline $\mathrm{C}$ & Cooling \\
\hline con & Condensation \\
\hline cycle & Cycle \\
\hline dry & Dry state \\
\hline ev & Evaporation \\
\hline $\mathrm{H}$ & Heating \\
\hline $\mathrm{H}_{2} \mathrm{O}$ & Water or water vapor \\
\hline hex & Heat exchanger \\
\hline in & Inlet \\
\hline out & Outlet \\
\hline re & Regeneration \\
\hline sor & Sorption \\
\hline sorb & Sorbent \\
\hline 0 & Start of cycle \\
\hline 1 & End of isosteric heating \\
\hline 2 & End of desorption phase \\
\hline 3 & End of isosteric cooling \\
\hline 4 & End of cycle \\
\hline
\end{tabular}




\section{References}

1. Oliveira, R.G.; Wang, R.Z. A consolidated calcium chloride-expanded graphite compound for use in sorption refrigeration systems. Carbon 2007, 45, 390-396. [CrossRef]

2. Jiang, L.; Gao, J.; Wang, L.; Wang, R.; Lu, Y.; Roskilly, A.P. Investigation on performance of multi-salt composite sorbents for multilevel sorption thermal energy storage. Appl. Energy 2017, 190, 1029-1038. [CrossRef]

3. Daou, K.; Wang, R.Z.; Xia, Z.Z. Development of a new synthesized adsorbent for refrigeration and air conditioning applications. Appl. Therm. Eng. 2006, 26, 56-65. [CrossRef]

4. Lu, Z.; Wang, R.Z.; Xia, Z.; Gong, L. Experimental investigation adsorption chillers using micro-porous silica gel-water and compound adsorbent-methanol. Energy Convers. Manag. 2013, 65, 430-437. [CrossRef]

5. Tokarev, M.M.; Gordeeva, L.G.; Grekova, A.D.; Aristov, Y.I. Adsorption cycle "heat from cold" for upgrading the ambient heat: The testing a lab-scale prototype with the composite sorbent $\mathrm{CaClBr} /$ silica. Appl. Energy 2018, 211, 136-145. [CrossRef]

6. Aristov, Y.I. New family of solid sorbents for adsorptive cooling: Material scientist approach. J. Eng. Thermophys. 2007, 16, 63-72. [CrossRef]

7. Okunev, B.N.; Aristov, Y.I. Making adsorptive chillers faster by a proper choice of adsorption isobar shape: Comparison of optimal and real adsorbents. Energy 2014, 76, 400-405. [CrossRef]

8. Sapienza, A.; Velte, A.; Girnik, I.; Frazzica, A.; Füldner, G.; Schnabel, L.; Aristov, Y. “Water-Silica Siogel” working pair for adsorption chillers: Adsorption equilibrium and dynamics. Renew. Energy 2017, 110, 40-46. [CrossRef]

9. Wittstadt, U.; Fuldner, G.; Andersen, O.; Herrmann, R.; Schmidt, F. A new adsorbent composite material based on metal fiber technology and its application in adsorption heat exchangers. Energies 2015, 8, 8431-8446. [CrossRef]

10. Gordeeva, L.; Frazzica, A.; Sapienza, A.; Aristov, Y.; Freni, A. Adsorption cooling utilizing the "LiBr/silica-Ethanol" working pair: Dynamic optimization of the adsorber/heat exchanger unit. Energy 2014, 75, 390-399. [CrossRef]

11. Vasta, S.; Freni, A.; Sapienza, A.; Costa, F.; Restuccia, G. Development and lab-test of a mobile adsorption air-conditioner. Int. J. Refrig. 2012, 35, 701-708. [CrossRef]

12. Freni, A.; Russo, F.; Vasta, S.; Tokarev, M.; Aristov, Y.I.; Restuccia, G. An advanced solid sorption chiller using SWS-1L. Appl. Therm. Eng. 2007, 27, 2200-2204. [CrossRef]

13. Gordeeva, L.G.; Freni, A.; Aristov, Y.I.; Restuccia, G. Composite sorbent of methanol "lithium chloride in mesoporous silica gel" for adsorption cooling machines: Performance and stability evaluation. Ind. Eng. Chem. Fund. 2009, 48, 6197-6202. [CrossRef]

14. Saha, B.B.; Chakraborty, A.; Koyama, S.; Aristov, Y.I. A new generation cooling device employing $\mathrm{CaCl}_{2}$-in-silica gel-water system. Int. J. Heat Mass Transf. 2009, 52, 516-524. [CrossRef]

15. Wang, L.W.; Wang, R.Z.; Oliveira, R.G. A review on adsorption working pairs for refrigeration. Renew. Sustain. Energy Rev. 2009, 13, 518-534. [CrossRef]

16. Aristov, Y.I. Challenging offers of material science for adsorption heat transformation: A review. Appl. Therm. Eng. 2013, 50, 1610-1618. [CrossRef]

17. Aristov, Y.I. Novel Materials for Adsorptive Heat Pumping and Storage: Screening and Nanotailoring of Sorption Properties. J. Chem. Eng. Jpn. 2007, 40, 1242-1251. [CrossRef]

18. Restuccia, G.; Freni, A.; Vasta, S.; Aristov, Y.I. Selective water sorbent for solid sorption chiller: Experimental results and modelling. Int. J. Refrig. 2004, 27, 284-293. [CrossRef]

19. Freni, A.; Sapienza, A.; Glaznev, I.S.; Aristov, Y.I. Experimental testing of a lab-scale adsorption chiller using a novel selective water sorbent "silica modified by calcium nitrate". Int. J. Refrig. 2012, 35, 518-524. [CrossRef]

20. Aristov, Y.I.; Sapienza, A.; Ovoshchnikov, D.S.; Freni, A.; Restuccia, G. Reallocation of adsorption and desorption times for optimisation of cooling cycles. Int. J. Refrig. 2012, 35, 525-531. [CrossRef]

21. Kurokawa, A.; Togawa, J.; Nabeshima, Y.; Nagano, K. The evaluation of the moisture sorption mechanism of chloride-impregnated Wakkanai Siliceous Shale. Kagaku Kogaku Ronbun 2011, 37, 394-399. [CrossRef] 
22. Liu, H.; Nagano, K.; Togawa, J. A composite material made of mesoporous siliceous shale impregnated with lithium chloride for an open sorption thermal energy storage system. Sol. Energy 2015, 111, 186-200. [CrossRef]

23. Wen, T.; Lu, L.; Dong, C.; Luo, Y. Investigation on the regeneration performance of liquid desiccant by adding surfactant PVP-K30. Int. J. Heat Mass Transf. 2018, 123, 445-454. [CrossRef]

24. Wen, T.; Lu, L.; Dong, C. Enhancing the dehumidification performance of LiCl solution with surfactant PVP-K30. Energy Build. 2018, 171, 183-195. [CrossRef]

25. Jiang, R.; Qin, F.G.F.; Yang, X.; Huang, S.; Chen, B. Performance analysis of a liquid absorption dehumidifier driven by jacket-cooling water of a diesel engine in a CCHP system. Energy Build. 2018, 163, 70-78. [CrossRef]

26. Bellos, E.; Tzivanidis, C.; Pavlovic, S.; Stefanovic, V. Thermodynamic investigation of $\mathrm{LiCl}_{-} \mathrm{H}_{2} \mathrm{O}$ working pair in a double effect absorption chiller driven by parabolic trough collectors. Therm. Sci. Eng. Prog. 2017, 3, 75-87. [CrossRef]

27. Pandya, B.; Kumar, V.; Patel, J.; Matawala, V.K. Optimum Heat Source Temperature and Performance Comparison of $\mathrm{LiCl}-\mathrm{H}_{2} \mathrm{O}$ and $\mathrm{LiBr}-\mathrm{H}_{2} \mathrm{O}$ Type Solar Cooling System. J. Energy Resour. Technol. 2018, 140, 051204. [CrossRef]

28. Bellos, E.; Tzivanidis, C.; Antonopoulos, K.A. Exergetic and energetic comparison of $\mathrm{LiCl}_{-} \mathrm{H}_{2} \mathrm{O}$ and $\mathrm{LiBr}-\mathrm{H}_{2} \mathrm{O}$ working pairs in a solar absorption cooling system. Energy Convers. Manag. 2016, 123, 453-461. [CrossRef]

29. Liu, H.; Nagano, K.; Morita, A.; Togawa, J.; Nakamura, M. Experimental testing of a small sorption air cooler using composite material made from natural siliceous shale and chloride. Appl. Therm. Eng. 2015, 82, 68-81. [CrossRef]

30. Freni, A.; Bonaccorsi, L.; Calabrese, L.; Caprì, A.; Frazzica, A.; Sapienza, A. SAPO-34 coated adsorbent heat exchanger for adsorption chillers. Appl. Therm. Eng. 2015, 82, 1-7. [CrossRef]

31. Girnik, I.S.; Grekova, A.D.; Gordeeva, L.G.; Aristov, Y.I. Dynamic optimization of adsorptive chillers: Compact layer vs. bed of loose grains. Appl. Therm. Eng. 2017, 125, 823-829. [CrossRef]

32. Nakabayashi, S.; Nagano, K.; Nakamura, M.; Togawa, J.; Kurokawa, A. Improvement of water adsorption ability of natural mesoporous material by impregnating with chloride salts for development of a new desiccant filter. Adsorption 2011, 17, 675-686. [CrossRef]

33. Aristov, Y.I.; Tokarev, M.M.; Restuccia, G.; Cacciola, G. Selective water sorbents for multiple applications, 2. $\mathrm{CaCl}_{2}$ confined in micropores of silica gel: Sorption properties. React. Kinet. Catal. Lett. 1996, 59, 335-342. [CrossRef]

34. Monnin, C.; Dubois, M.; Papaiconomou, N.; Simonin, J.-P. Thermodynamics of the $\mathrm{LiCl}+\mathrm{H}_{2} \mathrm{O}$ System. J. Chem. Eng. Data 2002, 47, 1331-1336. [CrossRef]

35. Aristov, Y.I.; Tokarev, M.M.; Cacciola, G.; Restuccia, G. Selective water sorbents for multiple applications, 1. $\mathrm{CaCl}_{2}$ confined in mesopores of silica gel: Sorption properties. React. Kinet. Catal. Lett. 1996, 59, 325-333. [CrossRef]

36. Aristov, Y.I.; Marco, G.D.; Tokarev, M.M.; Parmon, V.N. Selective water sorbents for multiple applications, 3. $\mathrm{CaCl}_{2}$ solution confined in micro- and mesoporous silica gels: Pore size effect on the "solidification-melting" diagram. React. Kinet. Catal. Lett. 1997, 61, 147-154. [CrossRef]

37. Kamali, A.R.; Fray, D.J.; Schwandt, C. Thermokinetic characteristics of lithium chloride. J. Therm. Anal. Calorim. 2010, 104, 619-626. [CrossRef]

38. Fiorentino, M.; Starace, G. The design of countercurrent evaporative condensers with the hybrid method. Appl. Therm. Eng. 2018, 130, 889-898. [CrossRef]

39. Starace, G.; Fiorentino, M.; Meleleo, B.; Risolo, C. The hybrid method applied to the plate-finned tube evaporator geometry. Int. J. Refrig. 2018, 88, 67-77. [CrossRef]

40. Ernest, D. Measurement Systems: Application and Design, 4th ed.; McGraw-Hill: New York, NY, USA, 1990.

(C) 2018 by the authors. Licensee MDPI, Basel, Switzerland. This article is an open access article distributed under the terms and conditions of the Creative Commons Attribution (CC BY) license (http:// creativecommons.org/licenses/by/4.0/). 